\title{
Oral Development and Pathology
}

\author{
Melinda B. Clark, MD, FAAP, David A. Clark, MD, FAAP \\ Department of Pediatrics, Albany Medical Center, Albany, NY
}

Background: The mouth is integral in the development of feeding, the initiation of digestion, and for speech and socialization. Signs of systemic disease and nutritional deficiencies often manifest in the mouth, and poor oral health can exacerbate many systemic conditions.

Methods: This review addresses the fetal development of the mouth, major anomalies, common minor physical findings, and pathologic conditions and their management.

Results: Pediatric practitioners have historically been poorly trained in diagnosis and management of oral conditions, so this article provides an overview of oral embryology and pathology, with a focus on hard and soft tissue disease identification, triage, and management. For primary prevention to be effective, pediatric providers must be knowledgeable about the process of dental caries, prevention of the disease, and available interventions, including fluoride.

Conclusion: The embryology and anatomy of the oral cavity are complex, and the mouth is crucial to many physiologic processes. Pediatric primary care providers are uniquely positioned to prevent, identify, and triage dental caries, the most common chronic disease of childhood.

Keywords: Abnormalities-mouth, dental caries, odontogenesis, pathology-oral

Address correspondence to David A. Clark, MD, FAAP, Department of Pediatrics, Albany Medical Center, 47 New Scotland Ave., Albany, NY 12208. Tel: (518) 262-5333. Email: clarkd@amc.edu

\section{INTRODUCTION}

The mouth reflects general health and well-being, such that you cannot "be healthy without a healthy mouth." 1 The mouth is where taste and chewing occur and is integral to digestion, respiration, speech, and socialization; it is also a mirror reflecting systemic processes and health. Signs of systemic disease and nutritional deficiencies often manifest in the mouth, and poor oral health can exacerbate many systemic conditions. Pediatric practitioners have historically been poorly trained in diagnosis and management of oral conditions, so this article provides an overview of oral embryology and pathology, with a focus on hard and soft tissue disease identification, triage, and management.

\section{OROFACIAL DEVELOPMENT}

The structures of the oral cavity derive from the first branchial arch. By the end of the fourth week of development, the frontonasal, 2 maxillary, and 2 mandibular processes are visible. The face and palate complete midline fusion between 6 and 12 weeks' gestation, and the upper lip fuses by 6 weeks' gestation. ${ }^{2}$

Failure of midline fusion during embryogenesis results in the spectrum of cleft lip, cleft palate, cleft lip and palate, and mucous cleft palate (Figure 1). The medial nasal tissues fuse to form the lip during weeks 5 to 6 of embryonic development; the anterior hard palate, alveolus, and philtrum form during weeks 6 to $10 .^{3}$ The maxillary prominences cre- ate the posterior hard palate as the soft palate and the uvula fuse during gestation weeks 10 to 12 . Cleft lip and palate are common congenital anomalies with a prevalence of 17 per 10,000 live births. ${ }^{4}$ The etiology of clefts remains poorly understood, although genetic, syndromic, and environmental factors have all been implicated. Cleft lip can be unilateral, bilateral (Figure 2), or median or of only the soft palate (mucous cleft), although midline lip cleft is rare. Isolated cleft palate is more common in females with no racial predilection. ${ }^{4}$ Cleft lip with palate is twice as common as isolated cleft palate, with an incidence greater in males and those of Asian and Caucasian descent. Cleft palate without cleft lip is more likely to be associated with a syndrome. ${ }^{3}$

Teratogen exposures implicated in cleft development include organic solvents and agriculture chemicals, especially pesticides, ${ }^{5}$ as well as viral infections, metabolic derangement, and illicit drugs. Antiepileptic medications associated with orofacial defects include diazepam, phenytoin, phenobarbital, topiramate, and lamotrigine..$^{5-7}$ Nutritional deficiencies in early pregnancy are also associated with increased cleft risk, the best known being folic acid, which is now recommended as a routine supplement in pregnancy. ${ }^{8}$ Supplementation is most beneficial early in the first trimester, with a reduction in midline defect rates by two-thirds in babies without a major chromosomal anomaly. ${ }^{9}$

Cleft lip and/or palate is associated with many genetic syndromes, including the spectrum of chromosome $22 q 11$, 


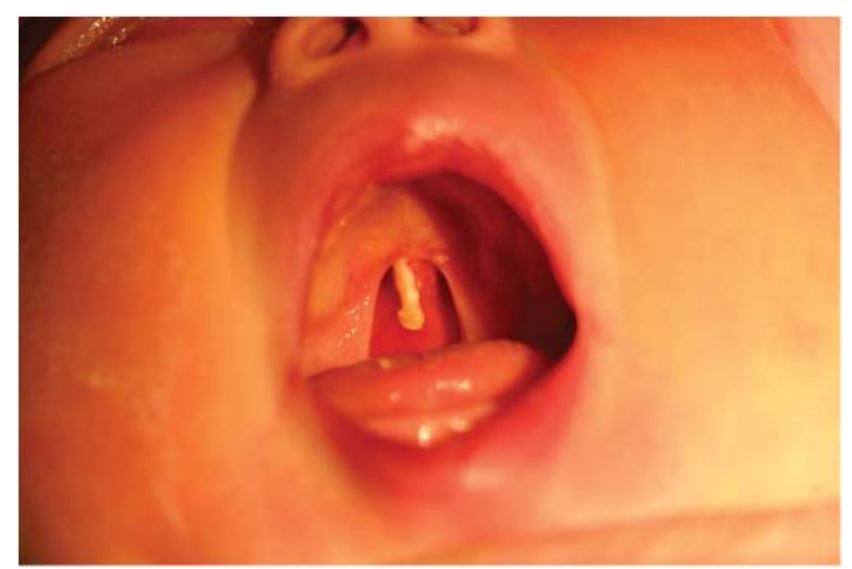

Figure 1. Mucous cleft palate.

oral-facial-digital syndrome, Treacher Collins syndrome, trisomy 13 (Figure 3), and Van der Woude syndrome. ${ }^{10} \mathrm{Cleft}$ palate can also result from embryonic tongue mechanical interference with palatal fusion, usually stemming from micrognathia with mandibular hypoplasia, known as Robin sequence or Pierre Robin syndrome.

Care of the neonate with cleft lip and/or palate requires genetic and hearing assessment, as well as airway evaluation and aggressive feeding support. ${ }^{11}$ Surgical primary lip repair is often undertaken around 3 months of age and primary palatal repair around 9 months. Residual hypernasal speech and language delays are common following completion of all surgeries. Optimal management is attained through a multidisciplinary cleft and craniofacial team comprised of experienced members of the medical, surgical, dental, and allied health disciplines.

Submucosal cleft palate is a mild or incomplete form of cleft palate. Examination may reveal a bifid uvula, muscular defect with overlying membrane, or a bluish mucosal line the length of the soft palate. ${ }^{12}$ Submucosal cleft palate is clinically challenging to detect but is often functionally significant, as the levator muscles must interdigitate across the palate to form the normal levator sling. The levator muscle must elevate to retract the posterior soft palate and divide the nasal and oral pharynxes to prevent velopharyngeal incompetence, which adversely impacts both feeding and speech.

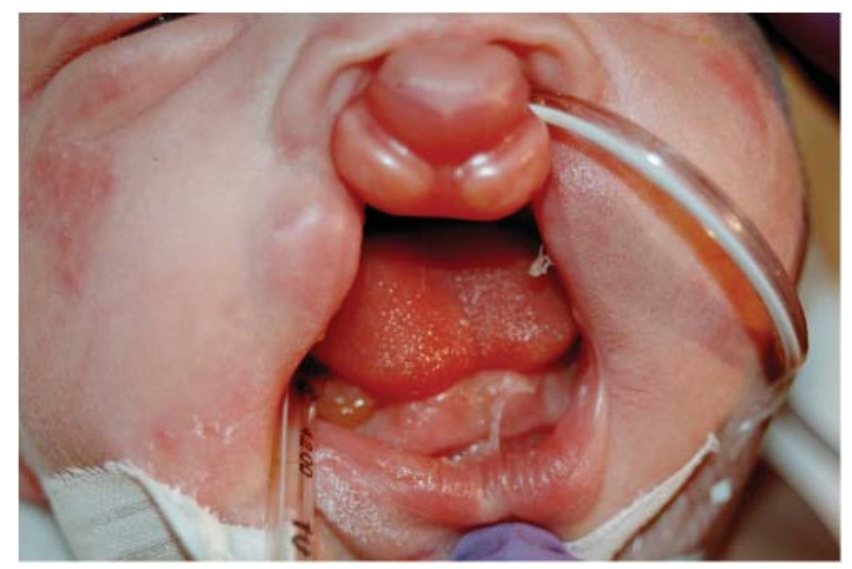

Figure 2. Bilateral cleft lip and palate.

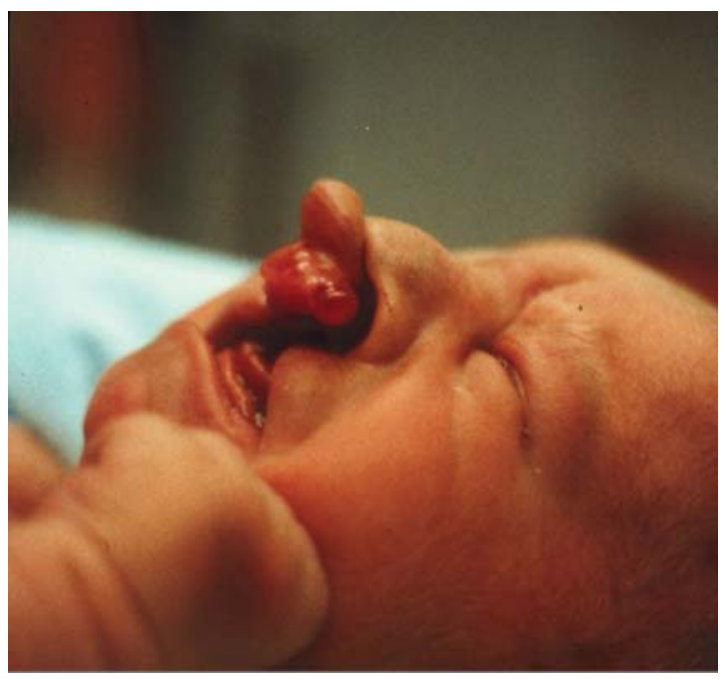

Figure 3. Trisomy 13 protruding cleft lip.

\section{SOFT TISSUE ANOMALIES}

Congenital soft tissue lesions of the oral cavity are quite common, and practitioners must be able to distinguish normal findings from those that require intervention. Epithelial tissue remnants form oral inclusion cysts ${ }^{13}$ that are small white or translucent papules or cysts seen in $75 \%$ of term newborns, although less commonly in premature infants. ${ }^{9}$ Asymptomatic inclusion cysts require no further evaluation or management and typically resolve by 3 months of age. Inclusion cysts are classified by their location. Epstein pearls, the most common of the 3 types, are found along the midline raphe of the hard palate in $75 \%-80 \%$ of all neonates. ${ }^{14}$ Bohn nodules are heterotopic salivary gland remnants seen on the buccal or lingual mucosal surface of the alveolar ridge (not the crest) or on the hard palate away from the raphe (Figure 4). Dental lamina cysts are heterotopic salivary gland remnants located on the crest of the alveolar ridge.

\section{ANKYLOGLOSSIA}

Ankyloglossia (tongue-tie) is anchoring of the tongue anteriorly. The frenulum connects near the tip of the tongue, limiting tongue extension to the lips or roof of the mouth,

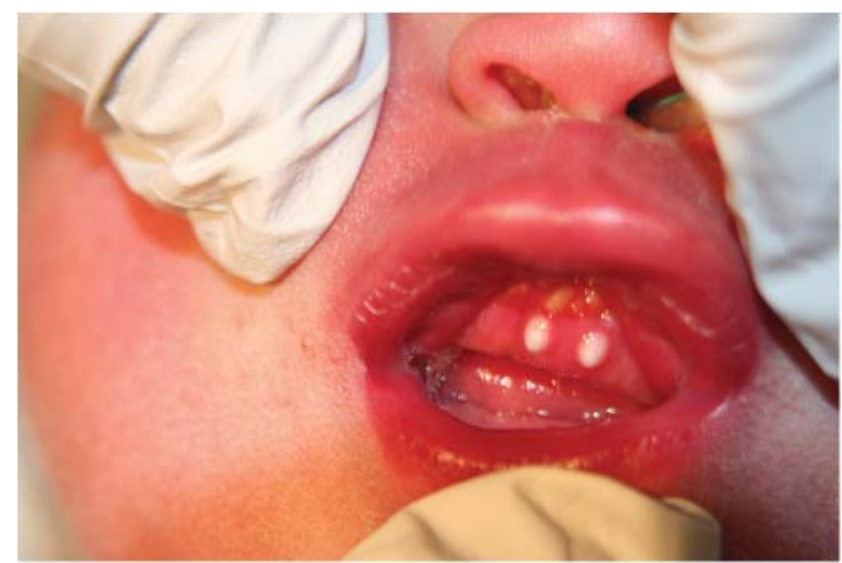

Figure 4. Bohn nodules. 
with a notched or heart-shaped tongue on protrusion. Ankyloglossia has a prevalence of $4 \%-10 \%$ but varies in severity and clinical impact, resulting in considerable debate regarding optimal management. ${ }^{15}$ Restricted tongue movement can lead to a variety of problems in infants and children, including challenges with breastfeeding latch, articulation delay, and compromised oral health. ${ }^{16,17}$

Initial symptoms of ankyloglossia include maternal nipple pain with breastfeeding, loss of suction, clicking sound while feeding, poor latch, and suboptimal milk transfer. ${ }^{18}$ Significant ankyloglossia can also contribute to articulation challenges but not a delay in absolute word production. ${ }^{19}$ Oral hygiene may be compromised with ankyloglossia, increasing the risk of dental caries and periodontal disease.

Management of ankyloglossia-related breastfeeding difficulties should include lactation specialist consultation, but frenectomy has been shown to improve breastfeeding for mother and newborn better than intensive lactation support alone. $^{20}$ Indications and timing of surgical division for ankyloglossia have been investigated, and in one randomized, prospective, unblinded trial of neonates with ankyloglossia and feeding concerns, all infants who received immediate division of the frenulum showed breastfeeding improvement, but only one neonate in the control group (intensive lactation support) improved. Frenotomy was then offered to and performed for the infants in the control group, and all but one baby improved and fed normally after the procedure. $^{20}$ Frenotomy can be performed with blunt scissors, cautery, or laser if a simple membrane is present, but frenuloplasty is preferred for more complex anatomy. ${ }^{21}$ Ankyloglossia is typically not indicative of underlying genetic syndrome, but absence of the inferior labial frenum and lingual frenulum is commonly noted in Ehlers-Danlos syndrome, and absence of the inferior labial frenum is strongly correlated with infantile hypertrophic pyloric stenosis. $^{22}$

Management of a constricted maxillary frenum is even more controversial. The maxillary frenum normally extends over the alveolar ridge to form a raphe. Persistence of the raphe during dental eruption can lead to diastema, or widely spaced central incisors. A prominent maxillary labial frenum may lead to esthetic concerns and to difficulty with plaque control which potentiates dental caries risk. Maxillary frenectomy is clearly indicated in rare cases when the frenum attachment exerts tension on the gingiva of a permanent tooth or if cosmesis is unacceptable following orthodontic closure of the diastema. ${ }^{23}$ Additional research is needed to better understand the appropriateness of performing preventive maxillary frenectomy on young children.

\section{DENTAL DEVELOPMENT AND DISEASE}

Humans are usually born edentulous, but tooth eruption may occur before birth (natal teeth) or within the first month of life (neonatal teeth) at a rate of $1: 2,000$ to 1:3,000 live births (Figure 5). ${ }^{24}$ Central mandibular incisors are most likely to prematurely erupt; these are usually primary dentition and not extra teeth, ${ }^{25}$ so they should not be extracted without cause. Management is usually observation, although extraction may be considered if teeth are mobile and present an aspiration risk, interfere with breastfeeding, or cause Riga-Fede ulceration. ${ }^{25}$ Natal teeth are most commonly an isolated finding but can be associated with genetic

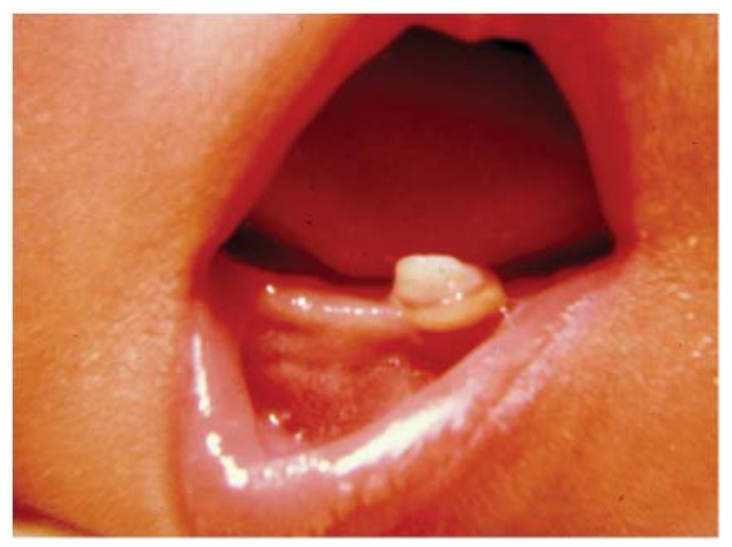

Figure 5. Natal tooth.

syndromes of chondroectodermal dysplasia (Ellis-van Creveld syndrome) and oculomandibulofacial syndrome (Hallermann-Streiff syndrome). ${ }^{26}$

Humans develop 2 sets of teeth, classifying us as diphyodont. The primary dentition begins developing in utero at week 8 of gestation, and the first primary teeth emerge between 6 and 12 months of age. The primary dentition is a complete set of 20 teeth by age 3 and consists of 8 incisors, 4 canines, and 8 molars. Primary teeth begin exfoliation at around 6 years of age, forced out by eruption of the permanent teeth. The permanent dentition consists of 32 teeth: 8 incisors, 4 canines, 8 premolars, and 12 total molars in 4 sets of 3 . The usual pattern of molar eruption is first molars between 6 and 8 years of age, second molars between ages 11 to 13 years, and third molars, or wisdom teeth, between ages 17 and 21 years.

Human teeth contain 4 distinct types of tissue: pulp, dentin, enamel, and cementum. The outermost layer of the tooth is made of enamel, the hardest tissue in the body, that withstands mechanical and thermal insults and protects against infection. Under the thin layer of enamel is dentin, the yellow substance forming the bulk of the tooth mass. The innermost portion of the tooth is the pulp, containing nerves and blood vessels that enter the root through a small hole in the tip. Teeth are held in place in the maxilla and mandible bones by a layer of cementum that covers the root.

\section{DENTAL CARIES}

Dental caries, also known as tooth decay, is the most common chronic disease of childhood, ${ }^{1}$ with $25 \%$ of children ages $2-5$ years $^{27}$ and $59 \%$ of teenagers having at least 1 documented cavity. ${ }^{28}$ Most adults develop cavities and, of great public health concern, nearly $25 \%$ of adults $20-64$ years have untreated dental caries. ${ }^{29}$ Dental caries in the primary teeth of children under 6 years of age is now termed early childhood caries (ECC), encompassing the previous nomenclature of nursing caries and baby bottle tooth decay. ECC is a multifactorial disease resulting from the interaction of cariogenic microorganisms and fermentable carbohydrates but impacted by a wide range of social variables. ${ }^{30}$

At the most basic level, dental caries requires 4 components: teeth, bacteria, carbohydrate exposure, and time. Teeth become colonized with cariogenic bacteria once they emerge. The bacteria metabolize carbohydrates and 
create acid as a byproduct. The acid dissolves, or demineralizes, the enamel and eventually wears away the enamel surface to create a hole in the tooth, termed a cavity. Once a cavity has formed, the bacteria can proceed through the outer tooth and into the pulp, resulting in pulpitis or abscess. If the infection is not contained and the tooth definitively treated, the dental abscess can progress to osteomyelitis of the jaw or spread to any contiguous soft tissue (face, neck, deep pharyngeal space, or brain) or the blood.

Dental caries is a silent epidemic that disproportionately affects those from the lower socioeconomic strata, those at the extremes of age, and minorities. ${ }^{31}$ Untreated tooth decay leads to pain, interrupted sleep, inappropriate use of overthe-counter medications, difficulty with chewing and eating, and increased hospitalizations resulting from infectious complications. ${ }^{31}$ Dental caries in the United States is responsible for many school and work hours lost per year ${ }^{32}$ and contributes to poor school performance. ${ }^{27}$ Good oral health is a necessary part of overall health, and studies have demonstrated the adverse effects of poor oral health on multiple other chronic conditions, including diabetes control. ${ }^{33}$ Therefore, failure to prevent dental disease has health, educational, and financial consequences at the individual, family, and societal levels.

Risk factors for ECC include having a mother/primary caregiver with active cavities, ${ }^{34}$ frequent consumption of sugary beverages and snacks, using a bottle at bedtime or through the night, prolonged frequent exposure to sugary liquids throughout the day, ${ }^{35}$ exposure to environmental tobacco smoke, ${ }^{36}$ having special healthcare needs, xerostomia, and insufficient fluoride exposure. ${ }^{37}$ Examination findings that increase the risk for development of ECC include visible plaque on the teeth and the presence of enamel hypoplasia. The most significant population-based risk factors are low socioeconomic status and low education and health literacy levels. ${ }^{38,39}$

Protective factors that aid in enamel remineralization include exposing the teeth to fluoride, limiting the frequency of carbohydrate consumption, choosing less cariogenic foods, practicing good oral hygiene, receiving regular dental care, and delaying bacterial colonization. ${ }^{37}$ If carious lesions are identified at the early white spot stage, the process can be halted or even reversed by modifying the individual's risk and protective factors.

Dental caries is preventable with proper oral hygiene, a healthy diet, appropriate use of fluoride, and access to preventive dental services. All children should establish a dental home by or around their first birthday, a recommendation supported by the American Academy of Pediatrics, American Academy of Pediatric Dentistry, American Dental Association, and American Public Health Association. ${ }^{27,37,39}$ Despite these recommendations, the Medical Expenditure Panel Survey revealed that $89 \%$ of infants and 1 -year-olds have office-based physician visits annually, compared with only $1.5 \%$ having dental visits. ${ }^{40}$ Because many children do not receive dental care at young ages, and risk factors for dental caries are influenced by parenting practices, pediatric primary care providers have a unique opportunity to participate in prevention of dental caries. The American Academy of Pediatrics recommends that primary care providers perform oral health assessments on all children starting at 6 months of age and recommends continued oral health assessments at routine visits through the age of 6 years. ${ }^{41}$ Screening oral examinations are most easily conducted in the knee-to-knee position with the child sitting facing the caregiver and lying back on the lap of the examiner. The oral examination should include visualization of all the hard and soft tissues, with focus on the teeth for enamel defects, presence of plaque, white spot lesions, overt decay, and gingival health. For primary prevention to be effective, pediatric providers must be knowledgeable about the process of dental caries, prevention of the disease, and available interventions, including fluoride.

Fluoride is effective in cavity prevention with 3 main effects of enhancing enamel remineralization, inhibiting demineralization, and inhibiting bacterial metabolism, thereby limiting acid production. The beneficial effect of fluoride is obtained by topical administration. Fluoride can be applied to tooth surfaces via fluoridated toothpaste, mouth rinses, fluoridated community water, dietary fluoride supplements, and fluoride varnish. The United States Preventive Services Task Force (USPSTF) recommended in 2014 that primary care clinicians apply fluoride varnish to the primary teeth of all infants and children starting at the age of primary tooth eruption. ${ }^{42,43}$ The USPSTF made this recommendation a grade $B$ recommendation; thus, the service must be covered by the Affordable Care Act and commercial payers without cost sharing. The 2014 American Academy of Pediatrics clinical report "Fluoride Use in Caries Prevention in the Primary Care Setting" provides a review of fluoride modalities, including recommending fluoride varnish application in the medical home 2-4 times per year for all children ages 5 and under. ${ }^{44}$ Oral health recommendations for screening, fluoride varnish, and fluoride supplements were added to the Bright Futures periodicity schedule in 2015 . $^{45}$

In June 2015, the Cochrane Oral Health group questioned the fluoridation of public water sources, especially in terms of its effectiveness for adults. The group asserted that older studies were poorly controlled and that more research is necessary. ${ }^{46}$ In a letter to healthcare professionals dated July 2, 2015, ${ }^{47}$ Katherine Weno, DDS, Director of the Division of Oral Health, Centers for Disease Control and Prevention $(C D C)$, responded forcefully in favor of water fluoridation, with her position supported by multiple studies. ${ }^{48-51}$ Five days later, the American Dental Association reinforced the position of the CDC. ${ }^{52}$

\section{CONCLUSION}

The embryology and anatomy of the oral cavity are complex, and the mouth is crucial to many physiologic processes. This review focused on common developmental and acquired defects: the spectrum of cleft lip and palate, soft tissue anomalies, ankyloglossia, and the most common disease of the hard tissues, dental caries. Historically, pediatric professionals have maintained ownership of soft tissue disease management, but this review highlights why and how pediatric primary care providers are uniquely positioned to prevent, identify, and triage dental caries, which remains the most common chronic disease of childhood.

\section{ACKNOWLEDGMENTS}

The authors have no financial or proprietary interest in the subject matter of this article. 


\section{REFERENCES}

1. Department of Health and Human Services. Oral health in America: a report of the surgeon general. Rockville, MD: National Institute of Dental and Craniofacial Research, National Institutes of Health; 2000. https://profiles.nlm.nih.gov/ps/access /NNBBJT.pdf. Accessed September 5, 2018.

2. Moore LM, Persaud TVN. The Developing Human: Clinically Oriented Embryology. 8th ed. Philadelphia, PA: Saunders; 2008.

3. Mai CT, Cassell CH, Meyer RE, et al; National Birth Defects Prevention Network. Birth defects data from population-based birth defects surveillance programs in the United States, 20072011: highlighting orofacial clefts. Birth Defects Res A Clin Mol Teratol. 2014 Nov;100(11):895-904. doi: 10.1002/bdra.23329.

4. Canfield MA, Honein MA, Yuskiv N, et al. National estimates and race/ethnic-specific variation of selected birth defects in the United States, 1999-2001. Birth Defects Res A Clin Mol Teratol. 2006 Nov;76(11):747-756.

5. Chevrier $C$, Dananché B, Bahuau $M$, et al. Occupational exposure to organic solvent mixtures during pregnancy and the risk of non-syndromic oral clefts. Occup Environ Med. 2006 Sep;63(9):617-623.

6. Yang W, Carmichael SL, Roberts EM, et al. Residential agricultural pesticide exposures and risk of neural tube defects and orofacial clefts among offspring in the San Joaquin Valley of California. Am J Epidemiol. 2014 Mar 15;179(6):740-748. doi: 10.1093/aje/kwt324.

7. Anderka M, Mitchell AA, Louik C, Werler MM, Hernández-Diaz S, Rasmussen SA; National Birth Defects Prevention Study. Medications used to treat nausea and vomiting of pregnancy and the risk of selected birth defects. Birth Defects Res A Clin Mol Teratol. 2012 Jan;94(1):22-30. doi: 10.1002/bdra.22865.

8. Sarmah S, Muralidharan P, Marrs JA. Common congenital anomalies: environmental causes and prevention with folic acid containing multivitamins. Birth Defects Res C Embryo Today. 2016 Sep;108(3):274-286. doi: 10.1002/bdrc.21138.

9. De-Regil LM, Peña-Rosas JP, Fernández-Gaxiola AC, RaycoSolon P. Effects and safety of periconceptional oral folate supplementation for preventing birth defects. Cochrane Database Syst Rev. 2015 Dec 14;(12):CD007950. doi: 10.1002/ 14651858.CD007950.pub3.

10. Jones KL. Recognizable patterns of malformation. In: Jones $\mathrm{KL}$, Jones JC, Del Campo M, eds. Smith's Recognizable Patterns of Human Malformation. $7^{\text {th }}$ ed. Philadelphia, PA: Elsevier Saunders; 2013:318-319.

11. Tighe D, Petrick L, Cobourne MT, Rabe H. Cleft lip and palate: effects on neonatal care. NeoReviews. 2011 Jun;12(6):e315e324.

12. Abbott MA. Cleft lip and palate. Pediatr Rev. 2014 May;35 (5):177-181. doi: 10.1542/pir.35-5-177.

13. Hayes PA. Hamartomas, eruption cyst, natal tooth and Epstein pearls in a newborn. ASDC J Dent Child. 2000 Sep-Oct;67(5):365368.

14. Donley CL, Nelson LP. Comparison of palatal and alveolar cysts of the newborn in premature and full-term infants. Pediatr Dent. 2000 Jul-Aug;22(4):321-324.

15. Messner AH, Lalakea ML. Ankyloglossia: controversies in management. Int J Pediatr Otorhinolaryngol. 2000 Aug 31;54(23):123-131.

16. Hogan M, Westcott C, Griffiths M. Randomized, controlled trial of division of tongue-tie in infants with feeding problems. $J$ Paediatr Child Health. 2005 May-Jun;41(5-6):246-250.

17. Lalakea ML, Messner AH. Ankyloglossia: does it matter? Pediatr Clin North Am. 2003 Apr;50(2):381-397.
18. Messner AH, Lalakea ML. The effect of ankyloglossia on speech in children. Otolaryngol Head Neck Surg. 2002 Dec;127(6):539545.

19. Ballard JL, Auer CE, Khoury JC. Ankyloglossia: assessment, incidence, and effect of frenuloplasty on the breastfeeding dyad. Pediatrics. 2002 Nov; 110(5):e63.

20. Buryk M, Bloom D, Shope T. Efficacy of neonatal release of ankyloglossia: a randomized trial. Pediatrics. 2011 Aug;128 (2):280-288. doi: 10.1542/peds.2011-0077.

21. Devishree, Gujjari SK, Shubhashini PV. Frenectomy: a review with the reports of surgical techniques. J Clin Diagn Res. 2012 Nov;6(9):1587-1592. doi: 10.7860/JCDR/2012/4089.2572.

22. De Felice C, Toti P, Di Maggio G, Parrini S, Bagnoli F. Absence of the inferior labial and lingual frenula in Ehlers-Danlos syndrome. Lancet. 2001 May 12;357(9267):1500-1502.

23. American Academy of Pediatric Dentistry. Council on Clinical Affairs. Guideline on Pediatric Oral Surgery. Revised 2014.

24. Cunha RF, Boer FA, Torriani DD, Frossard WT. Natal and neonatal teeth: review of the literature. Pediatr Dent. 2001 MarApr;23(2):158-162.

25. Bodenhoff J, Gorlin RJ. Natal and neonatal teeth: folklore and fact. Pediatrics. 1963 Dec;32(6):1087-1093.

26. Hattab FN, Yassin OM, Sasa IS. Oral manifestations of Ellis-van Creveld syndrome: report of two siblings with unusual dental anomalies. J Clin Pediatr Dent. 1998 Winter;22(2):159-165.

27. Centers for Disease Control and Prevention, National Center for Chronic Disease Prevention and Health Promotion. Oral Health at a Glance: 2016. U.S. Department of Health and Human Services. www.cdc.gov/chronicdisease/resources/publications /aag/oral-health.htm. Accessed September 11, 2018.

28. Tomar SL, Reeves AF. Changes in the oral health of US children and adolescents and dental public health infrastructure since the release of the Healthy People 2010 Objectives. Acad Pediatr. 2009 Nov-Dec;9(6):388-395. doi: 10.1016/j. acap.2009.09.018.

29. Dye BA, Thornton-Evans G. Trends in oral health by poverty status as measured by Healthy People 2010 Objectives. Public Health Rep. 2010 Nov-Dec;125(6):817-830.

30. Fisher-Owens SA, Gansky SA, Platt LJ, et al. Influences on children's oral health: a conceptual model. Pediatrics. 2007 Sep;120(3):e510-e520.

31. Casamassimo PS, Thikkurissy S, Edelstein BL, Maiorini E. Beyond the dmft: the human and economic cost of early childhood caries. J Am Dent Assoc. 2009 Jun;140(6):650-657.

32. Jackson SL, Vann WF Jr, Kotch JB, Pahel BT, Lee JY. Impact of poor oral health on children's school attendance and performance. Am J Public Health. 2011 Oct;101(10):1900-1906. doi: 10.2105/AJPH.2010.200915.

33. Mealey BL. Periodontal disease and diabetes. A two-way street. J Am Dent Assoc. 2006 Oct;137 Suppl:26S-31S.

34. Douglass JM, Li Y, Tinanoff N. Association of mutans streptococci between caregivers and their children. Pediatr Dent. 2008 Sep-Oct;30(5):375-387.

35. Tinanoff N, Palmer CA. Dietary determinants of dental caries and dietary recommendations for preschool children. J Public Health Dent. 2000 Summer;60(3):197-206; discussion 207-209.

36. B Hasmun NN, Drummond BK, Milne T, Cullinan MP, Meldrum AM, Coates D. Effects of environmental tobacco smoke on the oral health of preschool children. Eur Arch Paediatr Dent. 2017 Dec;18(6):393-398. doi: 10.1007/s40368-017-0308-6.

37. Section on Oral Health. Maintaining and improving the oral health of young children. Pediatrics. 2014 Dec;134(6):12241229. doi: 10.1542/peds.2014-2984. 
38. Fontana M. The clinical, environmental, and behavioral factors that foster early childhood caries: evidence for caries risk assessment. Pediatr Dent. 2015 May-Jun;37(3):217-225.

39. Congiu G, Campus G, Lugliè PF. Early childhood caries (ECC) prevalence and background factors: a review. Oral Health Prev Dent. 2014;12(1):71-76. doi: 10.3290/j.ohpd.a31216.

40. Stearns SC, Rozier RG, Kranz AM, Pahel BT, Quiñonez RB. Costeffectiveness of preventive oral health care in medical offices for young Medicaid enrollees. Arch Pediatr Adolesc Med. 2012 Oct;166(10):945-951.

41. American Academy of Pediatrics, Bright Futures Steering Committee. Promoting oral health. In: Hagan JF, Shaw JS, Duncan PM, eds. Bright Futures: Guidelines for Health Supervision of Infants, Children, and Adolescents. $3^{\text {rd }}$ ed. Elk Grove Village, IL: American Academy of Pediatrics; 2008:155-168.

42. Final summary: dental caries in children from birth through age 5 years: screening. U.S. Preventive Services Task Force. www .uspreventiveservicestaskforce.org/Page/Document /UpdateSummaryFinal/dental-caries-in-children-from-birth -through-age-5-years-screening. Released May 2014. Accessed September 5, 2018.

43. U.S. Department of Health and Human Services Federal Panel on Community Water Fluoridation. U.S. public health service recommendation for fluoride concentration in drinking water for the prevention of dental caries. Public Health Rep. 2015 JulAug;130(4):318-331.

44. Clark MB, Slayton RL; Section on Oral Health. Fluoride use in caries prevention in the primary care setting. Pediatrics. 2014 Sep;134(3):626-633. doi: 10.1542/peds.2014-1699.

45. Hagan JF, Shaw JS, Duncan PM, eds. Bright Futures: Guidelines for Health Supervision of Infants, Children, and Adolescents. $4^{\text {th }}$ ed. Elk Grove Village, IL: American Academy of Pediatrics; 2017.
46. Iheozor-Ejiofor Z, Worthington HV, Walsh T, et al. Water fluoridation for the prevention of dental caries. Cochrane Database Syst Rev. 2015 Jun;(6):CD010856. doi: 10.1002/ 14651858.CD010856.pub2.

47. Weno K. Comments regarding the Cochrane Review of Water Fluoridation for the Prevention of Dental Caries. Department of Health and Human Services, Centers for Disease Control and Prevention. July 2, 2015. http://www.ada.org/ /media/ADA /Public\%20Programs/Files/FL-CDC-Comments-Cochrane -Review.ashx. Accessed September 7, 2018.

48. Rugg-Gunn AJ, Do L. Effectiveness of water fluoridation in caries prevention. Community Dent Oral Epidemiol. 2012 Oct;40 Suppl 2:55-64. doi: 10.1111/j.1600-0528.2012.00721.x.

49. Brunelle JA, Carlos JP. Recent trends in dental caries in U.S. children and the effect of water fluoridation. J Dent Res. 1990 Feb;69 Spec No:723-727.

50. Griffin SO, Regnier E, Griffin PM, Huntley V. Effectiveness of fluoride in preventing caries in adults. J Dent Res. 2007 May;86 (5):410-415.

51. Slade GD, Sanders AE, Do L, Roberts-Thompson K, Spencer AJ. Effects of fluoridated drinking water on dental caries in Australian adults. J Dent Res. 2013 Apr;92(4):376-382. doi: 10.1177/0022034513481190.

52. The American Dental Association responds to Cochrane Review of Water Fluoridation [press release]. July 7, 2015. https://www .ada.org/en/press-room/news-releases/2015-archive/july/the -american-dental-association-responds-to-cochrane-review-of -water-fluoridation. Accessed September 7, 2018.

This article meets the Accreditation Council for Graduate Medical Education and the American Board of Medical Specialties Maintenance of Certification competencies for Patient Care, Medical Knowledge, and Practice-Based Learning and Improvement. 